\title{
Elaborating a framework for communicating assessment aims in higher education
}

\section{Damon Thomas, Robbie Moore, Olivia Rundle, Sherridan Emery, Robyn Greaves, Kitty te Riele \& Andy Kowaluk}

To cite this article: Damon Thomas, Robbie Moore, Olivia Rundle, Sherridan Emery, Robyn Greaves, Kitty te Riele \& Andy Kowaluk (2018): Elaborating a framework for communicating assessment aims in higher education, Assessment \& Evaluation in Higher Education, DOI: 10.1080/02602938.2018.1522615

To link to this article: https://doi.org/10.1080/02602938.2018.1522615

央 Published online: 26 Oct 2018.

Submit your article to this journal $\sqsubset \pi$

View Crossmark data ־ 


\title{
Elaborating a framework for communicating assessment aims in higher education
}

\author{
Damon Thomas $^{\mathrm{a}}$ (D), Robbie Moore ${ }^{\mathrm{a}}$ (D), Olivia Rundle ${ }^{\mathrm{a}}$ (D) Sherridan Emery ${ }^{\mathrm{a}}$ (D), \\ Robyn Greaves $^{c}$ (D), Kitty te Riele ${ }^{\mathrm{b}}$ (D) and Andy Kowaluk ${ }^{\mathrm{c}}$ (ID \\ ${ }^{a}$ College of Arts, Law and Education, University of Tasmania, Hobart/Launceston, Australia; ${ }^{\text {b Peter }}$ \\ Underwood Centre for Educational Attainment, University of Tasmania, Hobart, Australia; 'Department of \\ Education, University of Tasmania, Hobart, Tasmania, Australia
}

\begin{abstract}
Assessment is a central feature of student learning in higher education and has a strong influence on the student experience. Accordingly, the appropriate communication of assessment aims is a priority for all higher education institutions. This study proposes an analytical framework for the interpretation and creation of assessments across higher education disciplines. The framework suggests that assessments can be categorised according to rhetorical purposes, formats, modes and group arrangements. Assessments from three degree programmes at one Australian university are analysed using the framework to show its usefulness in classifying and evaluating task components and generating broad images of degrees based on assessment regimes. We draw on these practical applications to explain and compare discipline-specific qualities of each degree, and argue that the framework might enhance the communication of assessment aims to benefit higher education stakeholders.
\end{abstract}

\section{KEYWORDS}

Assessment design; higher education; assessment framework

\section{Assessment in higher education}

Assessment is at the heart of teaching and learning in higher education; it is highly influential in shaping the learning experience of students (Ramsden 2003), defining the content to be learnt and the processes used to learn it (Biggs and Tang 2011). Much has been written about the purposes served by assessment in higher education. One commonly described purpose of assessment is to provide students with certification of achievement; signifying 'a publicly acceptable code for quality' (Broadfoot and Black 2004, 9). This view of assessment of learning has long been associated with more summative means of assessment practice (Boud and Falchikov 2006).

A second purpose of assessment in higher education is to facilitate and direct student learning. From this perspective, assessments allow lecturers to evaluate and refine teaching and assist students to manage personal learning processes (Wiliam 2007; Villarroel et al. 2018). Assessment can promote student self-awareness of learning, help them to plan the next stages in their degrees, and facilitate student collaborations (Broadfoot and Black 2004). Over time, assessments allow students to learn about being members of different disciplines (Coffin et al. 2003). This purpose of assessment for learning has been associated with more formative means of assessment (Boud and Falchikov 2006). 
Recently, there have been calls for lecturers to design assessments that empower learners for their lives beyond tertiary education. Boud $(2000,151)$ described this as sustainable assessment: 'Assessment can be sustainable if it meets the needs of the present without compromising the ability of students to meet their own learning needs'. Similarly, McLean $(2018,2)$ argued that assessment should 'develop students' lifelong learning abilities for sophisticated relativist thinking and autonomous complex decision-making'. Such abilities are crucial if students are to successfully navigate the unexpected moral challenges of a globalised, complicated world.

\section{Assessment design in higher education}

The success of any assessment will be influenced its design. Bearman et al. $(2017,50)$ defined assessment design as a combination of processes, 'including the selection and timing of tasks, development of rubrics and redevelopment of a task in response to student performance'. The social context in which lecturers design assessments will influence decisions made about who and what is assessed, and why and how they are assessed (Broadfoot and Black 2004). Academic environments can enable or constrain effective assessment design, as lecturers manage tensions, agendas and requirements at institutional, departmental and personal levels (Meyer et al. 2010). The complexities of assessment purposes and design raise challenges to effective student learning in higher education.

\section{Challenges in designing assessments that promote sustainable student learning}

To address challenges in assessment design, Boud et al. (2010) offered seven propositions for reform in higher education. They suggested that assessment works best when: (1) it is used to engage students in productive learning; (2) feedback actively improves student learning; (3) students and lecturers become responsible partners in learning and assessment; (4) students are inducted into assessment practices and cultures of higher education; (5) assessment for learning is placed at the centre of subject and programme design; (6) assessment for learning is a focus for staff and institutional development; and (7) assessment provides inclusive and trustworthy representation of student achievement. However, Boud et al. (2010) did not discuss the importance of clear communication of assessment aims to assist students to meet the task requirements. This aspect of assessment design has been explored in limited studies (e.g. Coffin et al. 2003; de Silva Joyce et al. 2014), leading to suggestions about key components of assessments that should be clearly communicated.

Assessment design is more effective when lecturers explicitly communicate how students can meet assessment aims. With reference to writing, Coffin et al. $(2003,3)$ stated that:

Student academic writing is often an invisible dimension of the curriculum; that is, the rules or conventions governing what counts as academic writing are often assumed to be part of the 'common sense' knowledge students have, and are thus not explicitly taught within disciplinary courses. If students lack familiarity with these conventions, the assumption is often held that they will 'pick it up' as part of learning their subject knowledge.

Similar assumptions may exist for a majority of assessments in higher education institutions, even if these do not involve writing. The more variety in the kinds of assessment formats and modes within a degree, the greater the need to make explicit the lecturer's expectations around the communication of knowledge through assessment.

It is common practice for lecturers to describe assessment aims in unit outlines. In these assessment descriptions, lecturers use verbs as prompts, such as explain, argue or design to focus student learning. Many institutions refer to Bloom's taxonomy (Bloom et al. 1956) to guide this practice, using verbs to indicate levels of task complexity. Students make implicit judgements about the kinds of texts they create, based on the verbs (Coffin et al. 2003), which becomes 
Table 1. Key components in higher education assessments.

\begin{tabular}{|c|c|c|c|}
\hline Component & Guiding question & Description & Example \\
\hline Rhetorical purpose & Why? & The overt communicative purpose of the assessment & Persuasive \\
\hline Assessment format & What? & The way in which the assessment is arranged/set out & Essay \\
\hline Assessment mode & How? & The way in which meaning is communicated & Written \\
\hline Group arrangements & By whom? & $\begin{array}{l}\text { The requirement for the assessment to be completed } \\
\text { independently or collaboratively }\end{array}$ & Independent \\
\hline
\end{tabular}

problematic when verbs link to a variety of text types, depending on the overarching purpose of the assessment.

A study by de Silva Joyce et al. (2014) discussed how a reliance on verbs led students to misinterpret assessment aims. They surveyed students and analysed every assessment in a Bachelor of Education (Primary) degree at an Australian university, paying attention to whether tasks involved individual or group work, and the creation of various text types. The study found that the provision of clear instructions and supplementary materials were useful supports to students, while a lack of clear instructions and/or poorly set out instructions were barriers to success. They suggested that lecturers can better support learning by going beyond verbs and indicating the response types and structures required to respond to tasks successfully; however, stopped short of suggesting a framework or template to assist lecturers to communicate assessments in ways that promote student understanding. To address this gap, the current paper proposes the assessment in higher education framework (AHEF), which lecturers can use to make assessment aims more explicit.

\section{Analytical framework}

The AHEF was devised through a synthesis of accounts of assessment components and linguistic resources in research literature, to represent characteristic assessment features. As a pilot, the research team used the framework to analyse and categorise select assessments completed by Bachelor of Education (Primary) students at one Australian university, based on assessment descriptions within unit outlines. This process refined the framework, with components introduced and/or modified to account for the variety of assessments in this context.

Following research on communication and assessment by Coffin et al. (2003), Cope and Kalantzis (2009), Biggs and Tang (2011) and de Silva Joyce et al. (2014), we construe the following components in higher education assessments: rhetorical purposes, formats, modes and group arrangements (see Table 1). We propose that stakeholders can effectively design and interpret assessments that are organised into these component parts.

\section{Rhetorical purpose}

The rhetorical purpose of a written assessment refers to the overt communicative purpose of the text' (Coffin et al. 2003, 14). To include assessments communicated in modes other than writing, we extend the definition of rhetorical purposes to be the overt communicative purpose of the assessment. A task's rhetorical purpose may be invisible to students if not discussed explicitly (Coffin et al. 2003). Knowing the rhetorical purpose is crucial if students are to complete the assessment successfully. For instance, while many higher education disciplines have traditionally required students to construct essays across units, the rhetorical purposes for doing so can be quite different. One essay may emphasise the analytical contrasting and synthesising of information, while another may place greater emphasis on student voice and persuasion. A student's success on a task will depend upon how they meet its rhetorical purpose, which in turn relies upon clear communication of assessment aims. 
Table 2. Rhetorical purposes in higher education assessments.

\begin{tabular}{|c|c|c|}
\hline Rhetorical purpose & Definition & Typical instructions \\
\hline Descriptive & $\begin{array}{l}\text { Assessments that require students to provide } \\
\text { information or facts related to learn- } \\
\text { ing content }\end{array}$ & Describe; Record; Summarise; Define \\
\hline Analytical & $\begin{array}{l}\text { Assessments that require students to unpack } \\
\text { and organise information in multiple sour- } \\
\text { ces, often into categories, types or } \\
\text { relationships }\end{array}$ & $\begin{array}{l}\text { Analyse; Report; Relate; Compare; } \\
\text { Contrast; Synthesise; Explain }\end{array}$ \\
\hline Reflective & $\begin{array}{l}\text { Assessments that require students to reflect on } \\
\text { personal experiences, opinions, events } \\
\text { and learning }\end{array}$ & Reflect; Respond; React \\
\hline Persuasive & $\begin{array}{l}\text { Assessments that require students to present } \\
\text { one or more perspective(s) on a topic to } \\
\text { persuade others }\end{array}$ & $\begin{array}{l}\text { Argue; Persuade; Defend; Challenge; } \\
\text { Debate; Discuss; Critique }\end{array}$ \\
\hline Creative & $\begin{array}{l}\text { Assessments that require students to create } \\
\text { original, imaginary responses and narratives }\end{array}$ & Narrate; Recount; Imagine; Tell (a story) \\
\hline Responsive & $\begin{array}{l}\text { Assessments that require students to respond } \\
\text { to hypothetical situations or scenarios; often } \\
\text { taking on a vocational role }\end{array}$ & Respond; Apply; Review; Teach \\
\hline Design-based & $\begin{array}{l}\text { Assessments that require students to design or } \\
\text { plan a new text, resource or solution }\end{array}$ & $\begin{array}{l}\text { Design; Plan; Create; Generate; } \\
\text { Build; Plot }\end{array}$ \\
\hline Engagement-based & $\begin{array}{l}\text { Assessments that ask students to engage in } \\
\text { learning opportunities (e.g. attend tutorials, } \\
\text { contribute to group discussions) }\end{array}$ & $\begin{array}{l}\text { Prepare; Share; Participate; Attend; } \\
\text { Practice; Learn }\end{array}$ \\
\hline
\end{tabular}

We propose that assessments in the disciplines of education, law and English are designed to meet one or more of eight rhetorical purposes: descriptive, analytical, reflective, persuasive, creative, responsive, design-based and engagement-based. Conventionally, assessment descriptions have not explicitly stated the rhetorical purposes of tasks; however, these purposes have been signalled by the use of verbs (Coffin et al. 2003). Table 2 defines the rhetorical purposes and lists verbs that are often used to implicitly signal them in current practice. While Bloom's taxonomy (Bloom et al. 1956) uses verbs to indicate and classify cognitive processes into different levels of complexity, the AHEF is not arranged hierarchically. Instead, it aims to present possible rhetorical purposes served by assessments in higher education to assist students to address tasks appropriately. We see the two frameworks as compatible and useful in different ways.

\section{Assessment format}

The format of an assessment refers to the ways it is arranged or set out (Biggs and Tang 2011). Common assessment formats include essays, reports and journals, which are often referred to as text types (Thomson and Droga 2012). An investigation of pre-service teacher attitudes about assessments in Australia found that 'students were happy to complete assignments, if they were told the purpose for completing a particular type of assignment, and the format for presenting the assignment' (de Silva Joyce et al. 2014, 117). While students must use verbs to predict overarching rhetorical purposes, assessment formats are clearly stated in most assessment descriptions in current higher education contexts. Assessment formats can serve various rhetorical purposes, which emphasises the value in explicitly detailing both components in assessment descriptions.

\section{Assessment mode}

Lecturers require students to use a variety of communicative modes to complete assessments. Following Cope and Kalantzis $(2009,178)$, we suggest that assessments in higher education require students to communicate in one or more of the following six modes: 
1. Written language: handwriting, typing

2. Visual representation: still or moving images, sculpture, craft

3. Audio representation: music, ambient sounds, noises, alerts

4. Tactile representation: touch, smell, taste

5. Gestural representation: culturally recognisable physical acts, body movements (e.g. hands and arms, facial expressions, eye movements, gait), clothing, hair style, dance

6. Spatial representation: proximity, spacing, layout, architecture, landscape.

\section{Group arrangements}

Group arrangements refer to requirements for students to complete assessments independently or in groups. Group assessment has become an integral component of degree programmes around the world (Houldsworth and Mathews 2000), raising several affordances and challenges (Hughes 2002). It is possible for assessments to involve independent and group components, particularly when task design is more complex.

\section{Methodology}

\section{Data collection and analysis}

Following the pilot phase, the research team used the AHEF to analyse assessment tasks in three undergraduate degrees at one Australian university. Specifically, the team analysed assessment descriptions in all Bachelor of Education (Primary) units, core Bachelor of Laws units, and all English specialisation units for the Bachelor of Arts degree. The research team includes lecturers from the three selected disciplines, making it possible to access all necessary unit outline documents. If insufficient information was provided in task descriptions to code rhetorical purposes and assessment formats, additional information was sought from unit coordinators. As this is a pilot study, it is envisaged that the methods of investigation could be expanded to other disciplines, depending on the results this research uncovers.

\section{Case study research}

The multiple case study approach (Yin 2009) was used in this study to analyse assessments in the three selected disciplines. Within-case analysis was employed to identify characteristics of assessments in each discipline, followed by a cross-case comparison to consider the value of the proposed AHEF. The team discussed similarities and differences between cases, based on a systematic comparison between the data and theoretical accounts of assessments in higher education (de Silva Joyce et al. 2014). The developing analytical categories allowed the research team to interrogate the framework as the analysis occurred (Clarke and Hollingsworth 2002). The three cases contributed to our framework through explication of theoretical constructs related to patterns in assessment design and communication of assessment aims and requirements across the three disciplines.

The investigation focused on how assessment aims are communicated to students through task descriptions (de Silva Joyce et al. 2014), and on the applicability of the framework in distinct higher education disciplines. Our cases are presented using the following data analysis scheme, based on the key components outlined in Table 1.

1. Rhetorical purpose

2. Format

3. Mode

4. Group arrangements 
Table 3. Bachelor of Education (Primary) assessment rhetorical purposes.

\begin{tabular}{lcc}
\hline Rhetorical purpose & $\begin{array}{c}\text { No. of tasks designed to } \\
\text { meet rhetorical purpose }\end{array}$ & $\begin{array}{c}\text { \% of tasks designed to } \\
\text { meet rhetorical purpose }\end{array}$ \\
\hline Analytical & 41 & 22 \\
Reflective & 30 & 16 \\
Design-based & 29 & 16 \\
Responsive & 27 & 15 \\
Descriptive & 23 & 12 \\
Persuasive & 21 & 11 \\
Engagement-based & 9 & 5 \\
Creative & 5 & 3 \\
\hline
\end{tabular}

The trustworthiness of the analysis was enhanced by the piloting and refinement of the AHEF, prior to the analysis and categorisation of units in the three degrees (O'Leary 2004). The study employed data triangulation and investigator triangulation (Hussein 2009), with the team collaboratively analysing and comparing assessments to show the value of the framework for analysing assessments across diverse academic disciplines.

\section{Results}

\section{Case study 1: Assessments in a Bachelor of Education (Primary) degree}

The Bachelor of Education (Primary) is a four-year undergraduate degree. The team analysed 29 core units from the 2017 offering. The degree involves integrated and assessed professional experiences (i.e. school placements). Course learning outcomes are framed by Graduate Teacher Standards (Australian Institute for Teaching and School Leadership (AITSL) 2017), and threshold learning outcomes (TLOs) for Bachelor Level study of Education (Heath 2011). Successful completion of this degree requires graduate teachers to: (1) know students and how they learn; (2) know the content and how to teach it; (3) plan for and implement effective teaching and learning; (4) create and maintain supportive learning environments; (5) assess, provide feedback and report on student learning; (6) engage in professional learning; and (7) engage professionally with others. The TLOs for education are: knowledge; skills; application of knowledge and skills; communication; professional learning; and ethical and responsible professional practice. Lecturers are required to map alignment between assessments in each unit and the Graduate Teacher Standards.

\section{Rhetorical purpose}

Assessments in the Bachelor of Education (Primary) degree served a range of rhetorical purposes. While the largest proportion of tasks were analytical (22\%), students were required to complete similar amounts of reflective (16\%), design-based (16\%), responsive (15\%), descriptive (12\%) and persuasive (11\%) tasks. This reflects the multidisciplinary nature and professional requirements of education, and, in practical terms, would require students to master writing for a wide range of purposes. As assessment descriptions did not explicitly state the overarching rhetorical purpose of assessments, the variety of purposes may lead education students to misinterpret the intended aims of assessments. Table 3 indicates the proportion of assessments serving each rhetorical purpose.

From first to fourth year, education assessments had a relatively consistent focus on analytical tasks that required students to compare, contrast and synthesise information from a variety of sources. Planning and teaching in contemporary educational settings requires strong analytical skills, as teachers negotiate curricula and contextual requirements to design lessons that meet individual needs and interests of students (Hattie 2012). Synthesising relevant information into 


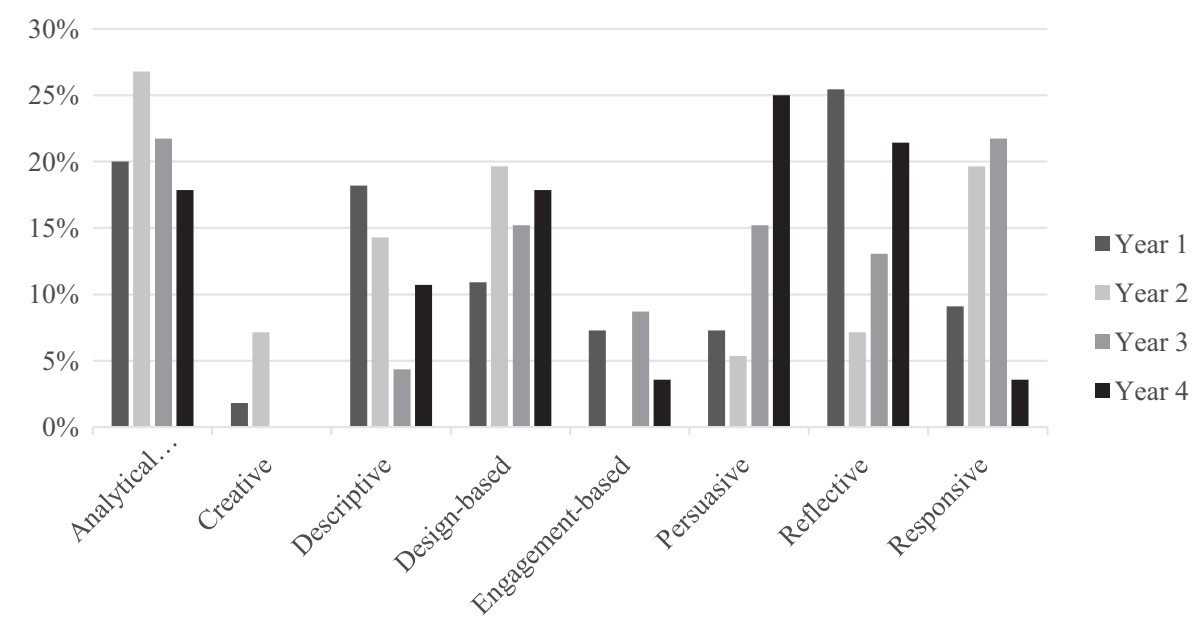

Figure 1. Bachelor of Education assessment rhetorical purposes by year of degree.

learning opportunities from the multitude of available resources demands that teachers have strong analytical skills. This justifies the focus on analytical tasks throughout the degree.

The education assessments also commonly required students to reflect on learning. While present in each year, reflective tasks strongly bookended the degree, with students asked to reflect on personal experiences as school learners in first year, and on university learning and school placements in fourth year. This emphasis seeks to foster students' reflective capabilities to become what Schon (1983) termed reflective practitioners. Ongoing, critical reflection represents a central mechanism in teacher change and development in classroom contexts (Clarke and Hollingsworth 2002).

The focus on descriptive tasks decreased across the degree, while there was a gradual increase in tasks requiring students to construct persuasive arguments and design educational resources/materials. These shifts reflect a developing knowledge of education theory, which equips students to successfully complete school placements and the initial years of teaching. The emphasis on each rhetorical purpose across the degree is presented in Figure 1.

\section{Assessment format}

Of the three degrees, education students were required to complete the largest range of assessment formats. Students were commonly required to write reflective journals, quiz responses, reports, rationales and lesson plans. The format of each assessment differed according to each educational discipline (i.e. the requirements and suggested format of a lesson plan in literacy education units varied from those in other disciplines such as science education). The variety of assessment formats completed by Education students is shown in Figure 2.

\section{Assessment modes}

Writing was privileged in education assessments, with $95 \%$ of tasks having a written component. By contrast, just under one quarter (24\%) of tasks had a visual component, with students creating blogs, digital artefacts and other texts that assessed their ability to design/arrange visual information. Only 7\% of assessments assessed students' oral language ability. The privileging of writing and the lack of oral assessments may disadvantage students who come from backgrounds that value oral communication above print-based media. The proportion of education assessments assessing each mode is presented in Table 4. 


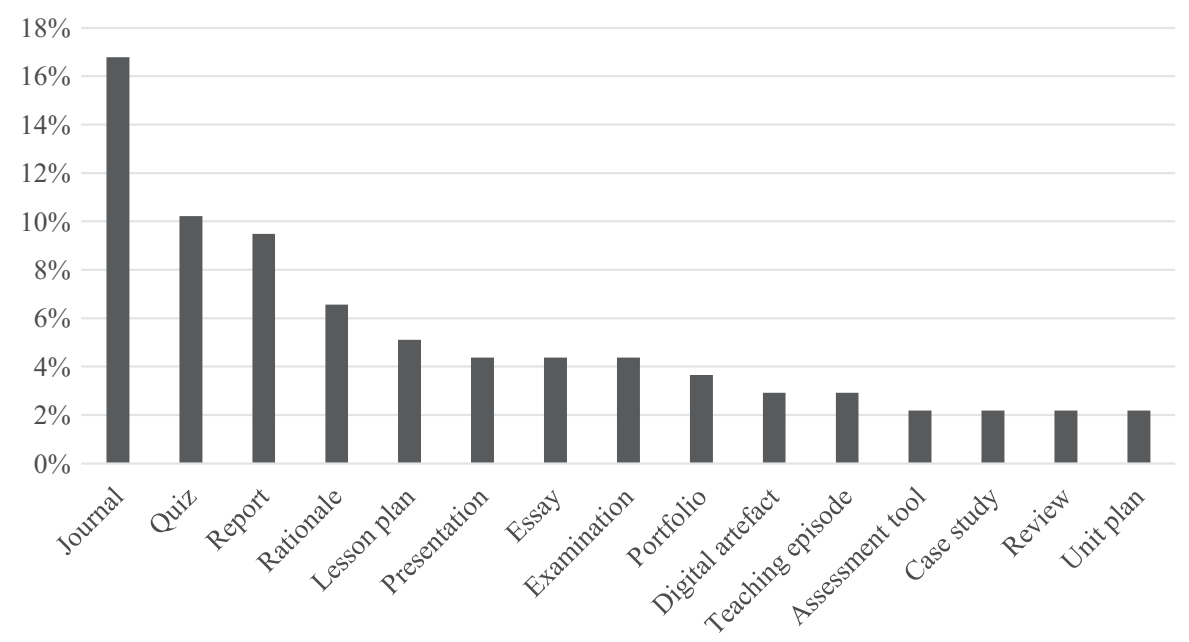

Figure 2. Bachelor of Education (Primary) assessment formats (accounting for $>2 \%$ of tasks).

Table 4. Bachelor of Education (Primary) assessments assessing each mode.

\begin{tabular}{lcc}
\hline Modes & No. of tasks assessing mode & \% of tasks assessing mode \\
\hline Written & 99 & 95 \\
Visual & 25 & 24 \\
Oral & 7 & 7 \\
Tactile & 2 & 2 \\
Audio & 1 & 1 \\
Oral & 1 & 1 \\
Spatial & 1 & 1 \\
\hline
\end{tabular}

\section{Group arrangements}

Very few assessments in the Bachelor of Education (Primary) degree assessed students in groups. Over the past three decades, there has been a shift in teacher practice from working in isolated classrooms to collaborative work in professional learning communities (Vescio, Ross, and Adams 2008). The privileging of independent assessments is logical in a tertiary context where students demonstrate their independent capacities as a beginning teacher; however, the lack of assessment opportunities that position students to develop collaborative skills may signal a mismatch between the requirements of a university degree and the realities of contemporary school teaching. The assessed group arrangements in the Bachelor of Education (Primary) degree are presented in Table 5.

\section{Case study 2: Assessments in the Bachelor of Laws degree}

The Bachelor of Laws is a four-year degree. We analysed all 20 core units from the 2017 offering. The law degree: prepares students for practical legal training if they plan to enter the legal profession; builds understanding of law for policy and managerial roles; and develops skills that can be applied in a wide range of contexts. Law schools rely upon recognition of law degrees by the practising legal profession to attract students. Regulation of law degrees by the higher education sector and the legal profession requires that students are taught and assessed in 11 subject areas and 6 TLOs for law (Australian Learning and Teaching Council 2010). The required areas of academic knowledge are: criminal law and procedure, torts, contract, property law, equity, company law, administrative law, constitutional law, civil dispute resolution, evidence, and ethics and professional responsibility. The TLOs for law are: knowledge, ethics and professional responsibility, thinking skills, research skills, communication and collaboration, and self-management. The 
Table 5. Bachelor of Education (Primary) assessment group arrangements.

\begin{tabular}{lcc}
\hline Group arrangement & No. of tasks with group arrangement & $\%$ of tasks with group arrangement \\
\hline Independent & 103 & 98 \\
Group & 2 & 2 \\
\hline
\end{tabular}

Table 6. Bachelor of Laws assessment rhetorical purposes.

\begin{tabular}{lcc}
\hline Rhetorical purpose & $\begin{array}{c}\text { No. of tasks designed to } \\
\text { meet rhetorical purpose }\end{array}$ & $\begin{array}{c}\% \text { of tasks designed to } \\
\text { meet rhetorical purpose }\end{array}$ \\
\hline Analytical & 57 & 30 \\
Persuasive & 53 & 28 \\
Responsive & 49 & 26 \\
Engagement-based & 16 & 8 \\
Descriptive & 11 & 6 \\
Reflective & 3 & 2 \\
\hline
\end{tabular}

areas of academic knowledge and TLOs are contained within the core unit offerings that we analysed in our study, to ensure graduates satisfy the pre-admission subject area requirements and TLOs.

\section{Rhetorical purpose}

Assessments in the law degree commonly served analytical, persuasive and responsive rhetorical purposes, which are core legal skills. The law discipline revolves around legal research, communication and analysis (Ehrenberg 2017), with lawyers applying their analysis of legal issues to factual scenarios to engage in legal reasoning and persuade decision makers (Fisher, Ury, and Patton 1991). Tasks with descriptive, engagement-based and reflective purposes were less prevalent, but present in the degree. Table 6 shows the proportion of each rhetorical purpose in the law degree.

Across the degree, analytical tasks were adopted consistently, keeping with the repetitive practice of legal analysis that is core work of legal experts. Legal analysis of problems can be complex and technical, with legal writers analysing, synthesising and simplifying information to suit audiences (Baron and Corbin 2016). This involves selecting valuable facts, issues and arguments, making judgements about levels of detail to provide, and keeping communication brief and clear (Goodman 2012). Given the complexity of this work, the emphasis on analytical tasks throughout the degree was appropriate.

Assessments serving the persuasive rhetorical purpose were also a common feature across the degree, particularly in the first year when it outweighed all other purposes. Persuasion is integral in the legal discipline, with most legal communication aiming to convince decision makers about decisions they will make (Wolski 2009). Knowing who is to be persuaded is the foundational question in any planned persuasion, as it enables an empathic consideration of the audience's needs, knowledge, capacity and point of view (Baron and Corbin 2016).

The degree's early years were also characterised by descriptive tasks, requiring students to identify and describe relevant legal issues. As students are gradually inducted into the legal discipline, descriptive tasks are outweighed by responsive tasks. This shift aims to allow students to build competency in applying legal issues to hypothetical scenarios as they near legal practice, moving from theory to practical applications. The spread of rhetorical purposes across the degree is presented in Figure 3.

\section{Assessment format}

A wide variety of assessment formats were assigned to law students in their units. The common formats were legal problem-solving assignments, examinations, quizzes, graded discussions and 


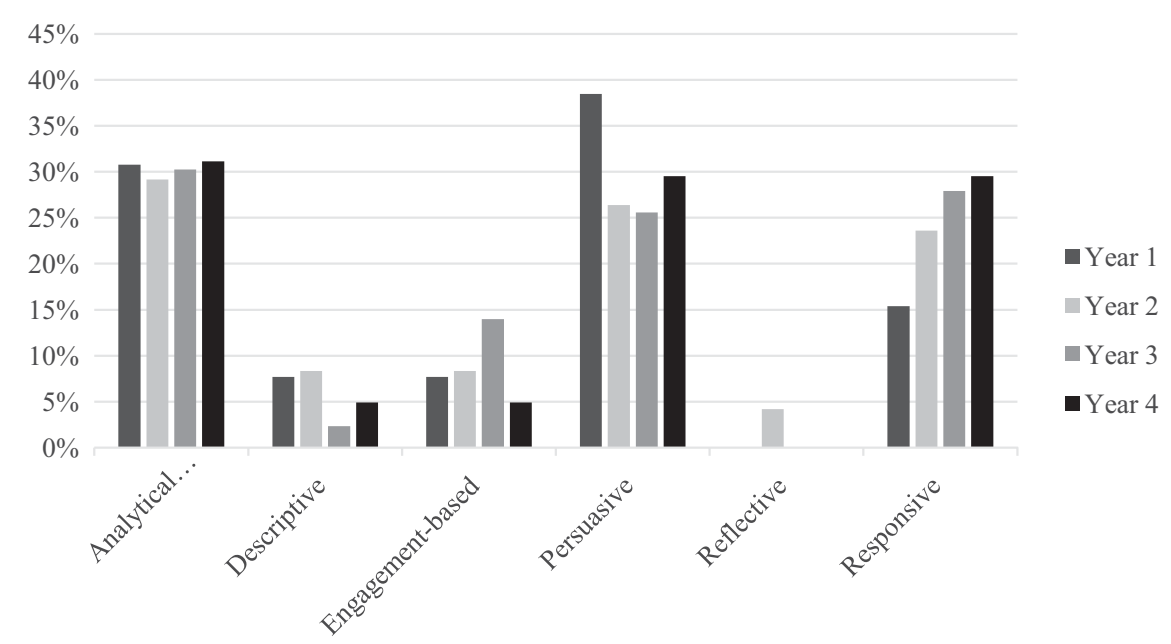

Figure 3. Bachelor of Laws assessment rhetorical purposes by year of degree.

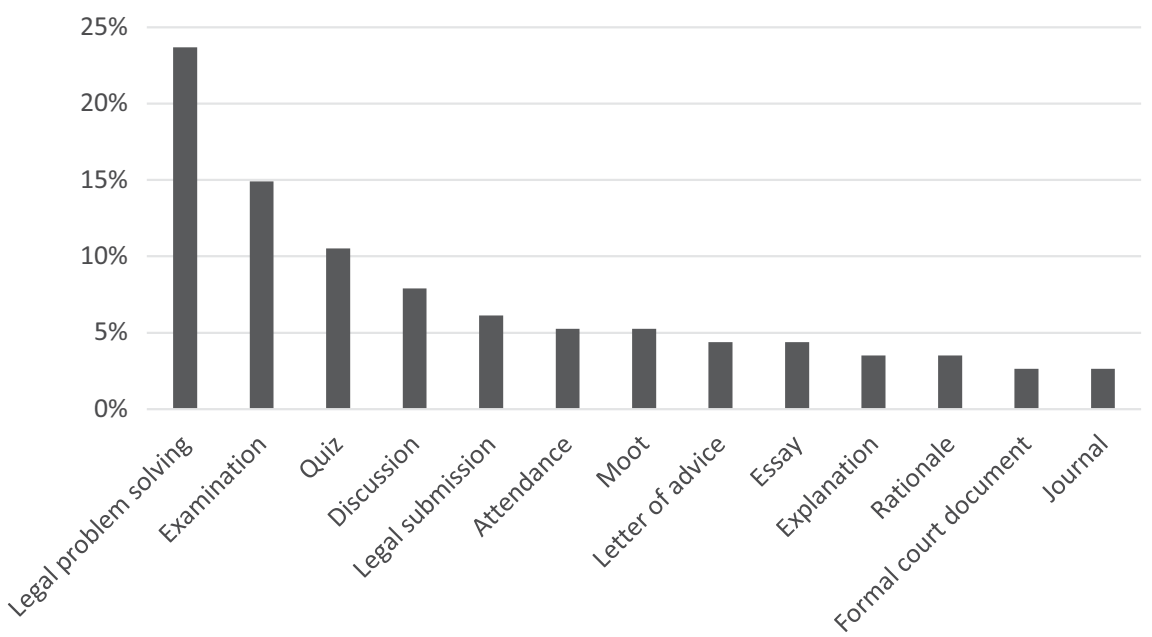

Figure 4. Bachelor of Laws assessment formats (accounting for $>2 \%$ of tasks).

moots. However, other assessment formats included letters of advice, essays, explanations, rationales, formal court documents, journals, court reports, case studies, performances, trial notebooks and legal judgements. Many of these formats were unique to the law degree. They reflect the sorts of communicative activities in which practising lawyers typically engage. The first year of the degree had 7 formats, compared to 16 in the fourth year, which may in part be explained by there only being two compulsory first year law units, but may also indicate a diversification of assessment formats throughout the degree. The proportions of assessment formats are presented in Figure 4.

\section{Assessment mode}

Law is a discipline that relies upon written communication of legal advice, argument, decisions and offers of resolution (Goodman 2012). It was therefore unsurprising that $79 \%$ of assessments involved the written mode. Just over one-quarter of law assessments assessed students' oral language skills (26\%), which are also core to the practice of law. Oral communication is the most common mode used to work with clients, present arguments to courts, and negotiate. Eleven 
Table 7. Bachelor of Laws assessments assessing each mode.

\begin{tabular}{lcc}
\hline Mode & No. of tasks assessing mode & \% of tasks assessing mode \\
\hline Written & 64 & 79 \\
Oral & 21 & 26 \\
Spatial & 9 & 11 \\
Gestural & 1 & 1 \\
Visual & 1 & 1 \\
\hline
\end{tabular}

Table 8. Bachelor of Laws assessment group arrangements.

\begin{tabular}{lcc}
\hline Group arrangement & No. of tasks with group arrangement & $\%$ of tasks with group arrangement \\
\hline Independent & 71 & 86 \\
Group & 12 & 14 \\
\hline
\end{tabular}

percent of the core law assessments involved the spatial mode, as students were assessed for engagement in tutorials. These assessments sometimes assessed the quality of student contributions, while others simply rewarded students for being present. This percentage demonstrates how the number of units that include a mark for attendance can become a considerable proportion of assessment across a whole degree. Table 7 presents the spread of assessment modes assessed during the Bachelor of Laws degree.

\section{Group arrangements}

As university degrees are awarded to individuals, one would expect most assessments to be submitted independently. Accordingly, $86 \%$ of law assessments were independent. However, one of the Law TLOs is for students to collaborate effectively, and furthermore, law graduates are expected to have capacity to work in teams. It was therefore appropriate to see $14 \%$ of the core law assessments were completed and submitted in groups. The assessed group arrangements in the Bachelor of Laws degree are presented in Table 8.

\section{Case study 3: Assessments in the English major units of a Bachelor of Arts degree}

The discipline of English can be studied at the higher education institution as a major in the Bachelor of Arts, a three-year undergraduate degree. We analysed assessments in the 11 units that comprised the English major in 2017. The discipline does not yet have a nationally agreed and endorsed set of TLOs, although TLOs have been drafted by the peak body for tertiary English, the Australian University Heads of English. These TLOs emphasise knowledge (of texts, periods, contexts, forms, theories and methods); skills (interpreting, using critical resources, constructing arguments); and professional capabilities (communication, and interpreting the social world) (Office for Learning and Teaching 2014). These draft TLOs have been adopted as the English major's intended learning outcomes (ILOs). The assessments of the English units align with these ILOs.

\section{Rhetorical purpose}

The rhetorical purposes of English assessments were overwhelmingly analytical (42\%) and persuasive (29\%). These purposes often coincided. Smaller proportions of assessments were creative (3\%), descriptive (4\%), engagement-based (10\%) and reflective (12\%). Analytical and persuasive tasks were frequently positioned as final, summative tasks in units, while creative, descriptive, engagement-based and reflective tasks were frequently formative, providing scaffolding around larger analytical and persuasive tasks. The centrality of analytical and persuasive tasks made visible by the AHEF suggests that students will become increasingly familiar with a characteristic 
Table 9. English major assessment rhetorical purposes.

\begin{tabular}{lcc}
\hline Rhetorical purpose & $\begin{array}{c}\text { No. of tasks designed to } \\
\text { meet rhetorical purpose }\end{array}$ & $\begin{array}{c}\% \text { of tasks designed to } \\
\text { meet rhetorical purpose }\end{array}$ \\
\hline Analytical & 29 & 42 \\
Persuasive & 20 & 29 \\
Reflective & 8 & 12 \\
Engagement-based & 7 & 10 \\
Descriptive & 3 & 4 \\
Creative & 2 & 3 \\
\hline
\end{tabular}

genre of English assessment, with less risk that students will misinterpret the intended aims of assessments. However, it also suggests that mastery of analytical and persuasive skills will be a major hurdle for English students, particularly in their first year as they adjust to new requirements and expectations. Table 9 indicates the proportion of assessments serving each rhetorical purpose.

The AHEF shows that analysis is the bedrock of the English major, with an unchanging focus on analytical tasks throughout the degree. Assessments each year required students to read texts critically, identify key concepts and issues, gather and present evidence, and evaluate and synthesise secondary sources. This emphasis is not unexpected. As a discipline, English is primarily concerned with critical thinking: with 'the analysis and evaluation of ideas, theories and processes - in challenging, questioning and creating knowledge' (Chambers and Gregory 2006, 157). Though English is not a vocational discipline, it develops skills of value in graduate employment, including 'high-order critical, analytic and research skills' (Quality Assurance Agency for Higher Education 2015, 5).

Persuasion was the other key rhetorical purpose in the sampled English assessments. Persuasion is key because English is not a discipline that deals with solid facts or absolutes: interpretations of a text 'are not right or wrong but better or worse, persuasive or not' (Linkon 2011, xii). English is, moreover, a discipline concerned with the rhetoric and style of argumentation, and values and fosters fluent and effective communication. The analysis indicated that persuasion became a more prominent rhetorical purpose in second year English assessments, suggesting that the development of an authoritative voice and the deployment of persuasive arguments are considered more advanced skills than the business of critical reading, which is the central focus of first year study.

In first year units, creative and reflective tasks are more prominent. Creative tasks (allowing students to rewrite or reimagine texts) and reflective tasks (encouraging students to journal and reflect on their own reading) were employed at the introductory level to 'use subjective engagement with the text in a productive way', and to help students 'move from emotionally charged first impressions' to 'analytical evaluation' (Gibson 2017, 106). The broad narrative of assessment that the AHEF charts, therefore, moves from the personal to the critical, and then to argument and persuasion. The emphasis on each rhetorical purpose across the degree is presented in Figure 5.

\section{Assessment format}

In contrast to education, English assessments centred on a single format: the essay, representing $30 \%$ of assessments, and occupying a privileged position in most units. Several other researchfocussed formats (research plans, annotated bibliographies, literature reviews), were set as formative tasks feeding directly into the production of a final essay. Like law, the AHEF suggested that assessment diversification and specialisation took place in intermediate and advanced units, while the standalone essay was more dominant in first year units. With its focus on the essay format, and formats which scaffold the essay, this English major is not unique. The research essay, eclipsing the examination, remains broadly entrenched in the discipline of English. The qualities 


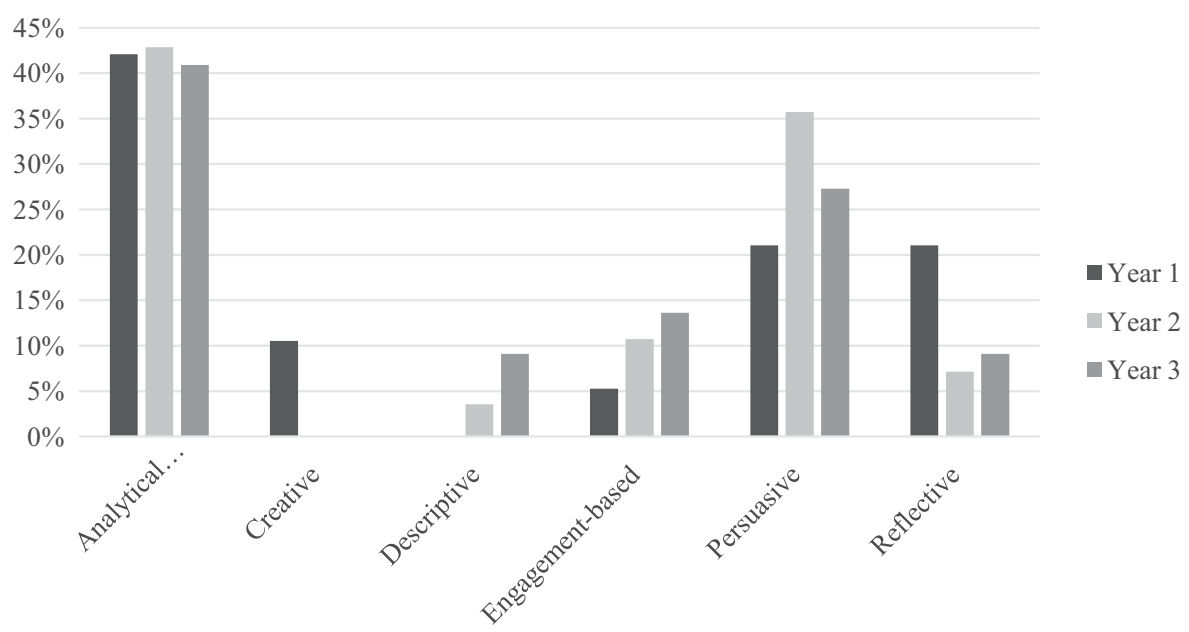

Figure 5. English major assessment rhetorical purposes by year of degree.

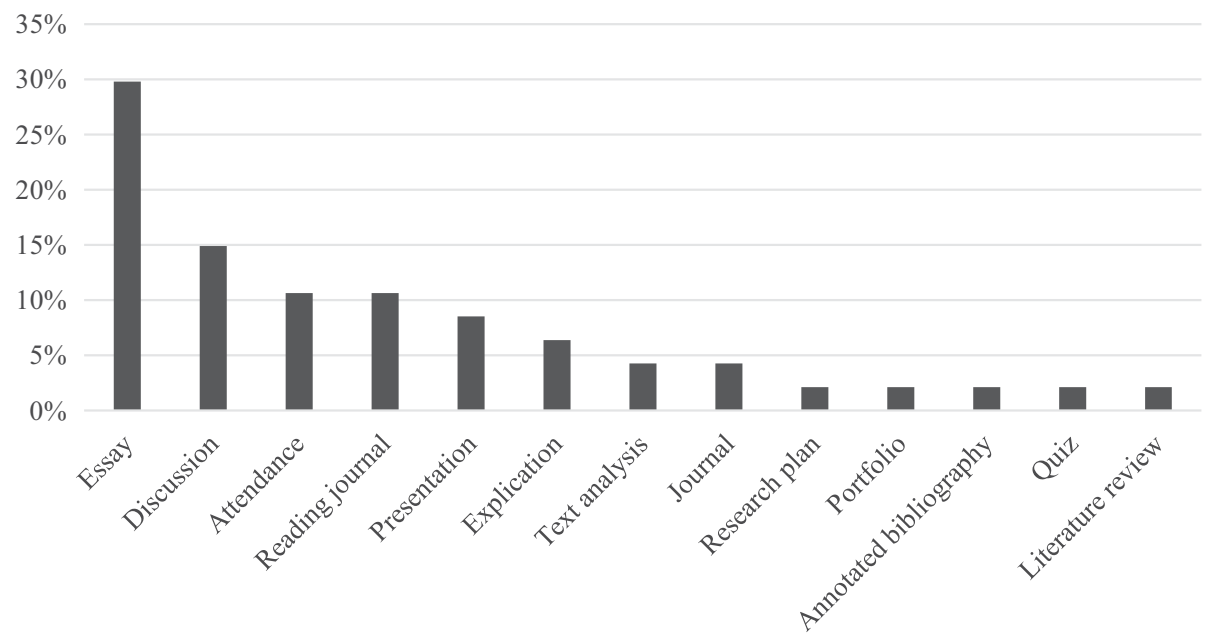

Figure 6. English major assessment formats.

that make the essay ideally suited for English studies - the openness and flexibility of its form, and its capacity for complexity and nuance - is exactly what makes it difficult to pin down with assessment criteria (Gibson 2017, 101; Knights 2017, 116). Articulating concrete expectations for essay composition is a central challenge for assessment regimes in English (Figure 6).

\section{Assessment modes}

Like education and law, tasks involving a written component were privileged in English assessments: $94 \%$ of tasks had a written component. A significant proportion of assessments, 30\%, assessed oral presentation skills. With the rise of the digital humanities, and the increasing recognition of multimodal literacy and multimedia competencies as valuable learning outcomes (Battershill and Ross 2017, 136), the English programme integrates blended learning modalities and multimedia resources in its teaching practice. The AHEF shows that this multimedia focus is not substantially reflected in its assessments, with $12 \%$ of assessments incorporating a visual component and $3 \%$ an audio component. A lack of diversity in assessment modes raises questions about accessibility and the need to cater to students with a variety of learning styles and 
Table 10. English major assessments assessing each mode.

\begin{tabular}{lcc}
\hline Mode & No. of tasks assessing mode & $\%$ of tasks assessing mode \\
\hline Written & 31 & 94 \\
Oral & 10 & 30 \\
Spatial & 5 & 15 \\
Visual & 4 & 12 \\
Audio & 1 & 3 \\
\hline
\end{tabular}

Table 11. English major assessment group arrangements.

\begin{tabular}{lcc}
\hline Group arrangement & No. of tasks with group arrangement & $\%$ of tasks with group arrangement \\
\hline Independent & 33 & 100 \\
Group & 0 & 0 \\
\hline
\end{tabular}

needs (Battershill and Ross 2017, 44). The proportion of English assessments assessing each mode is presented in Table 10.

\section{Group arrangements}

All analysed English units were individualised, with no group work component in any assessment. As Battershill et al. $(2017,54)$ argued, collaborative work in the humanities 'has traditionally been discouraged, both institutionally and as an affective category bred in the bone of academic reward systems'. Of all disciplines, literary studies is the most dominated by the soleauthor research model, and as Leane, Fletcher, and Garg $(2017,2)$ argue, 'Literary studies researchers themselves are surprisingly unreflective about their own academic authorship traditions and practices'. The AHEF suggests that the tradition of English studies as a heroically individualised practice begins at the undergraduate level with its assessment regimes. The assessed group arrangements in English are presented in Table 11.

\section{Discussion}

The purpose of this study was to identify an analytical framework that could be used to interpret, create and communicate assessment requirements in higher education contexts. The framework brought together key components of assessment design, informed by reviews of relevant literature and three Australian case studies. A cross-case comparison of education, law and English degrees at one Australian university illustrated a range of distinctive and overlapping features, distinguishing each discipline and assessment regime. Each case reflected the complexity of assessment design and interpretation in higher education (Bearman et al. 2017), and highlighted that a consistent approach to categorising and communicating assessment components might enhance a variety of assessment processes.

Analytical tasks were identified as the main rhetorical purpose for assessment in the three cases, making up the highest percentage of assessments in education (22\%), law (30\%) and English (42\%). Analytical assessments characterised all year levels in each degree, while other rhetorical purposes varied in use depending on the stage of a given degree. The AHEF identified a variety of rhetorical purposes in the degrees, with law and English favouring subsets of purposes (analytical, persuasive and responsive in law, and analytical and persuasive in English), and education involving most of the rhetorical purposes.

The analyses identified patterns in the use of assessment formats that were strongly discipline-specific. Assessments in education and law were often vocationally focused (e.g. lesson plans in education, legal problem solving in law), particularly later in the degrees, while English privileged traditional essays. A group of five assessment formats were common across the three 


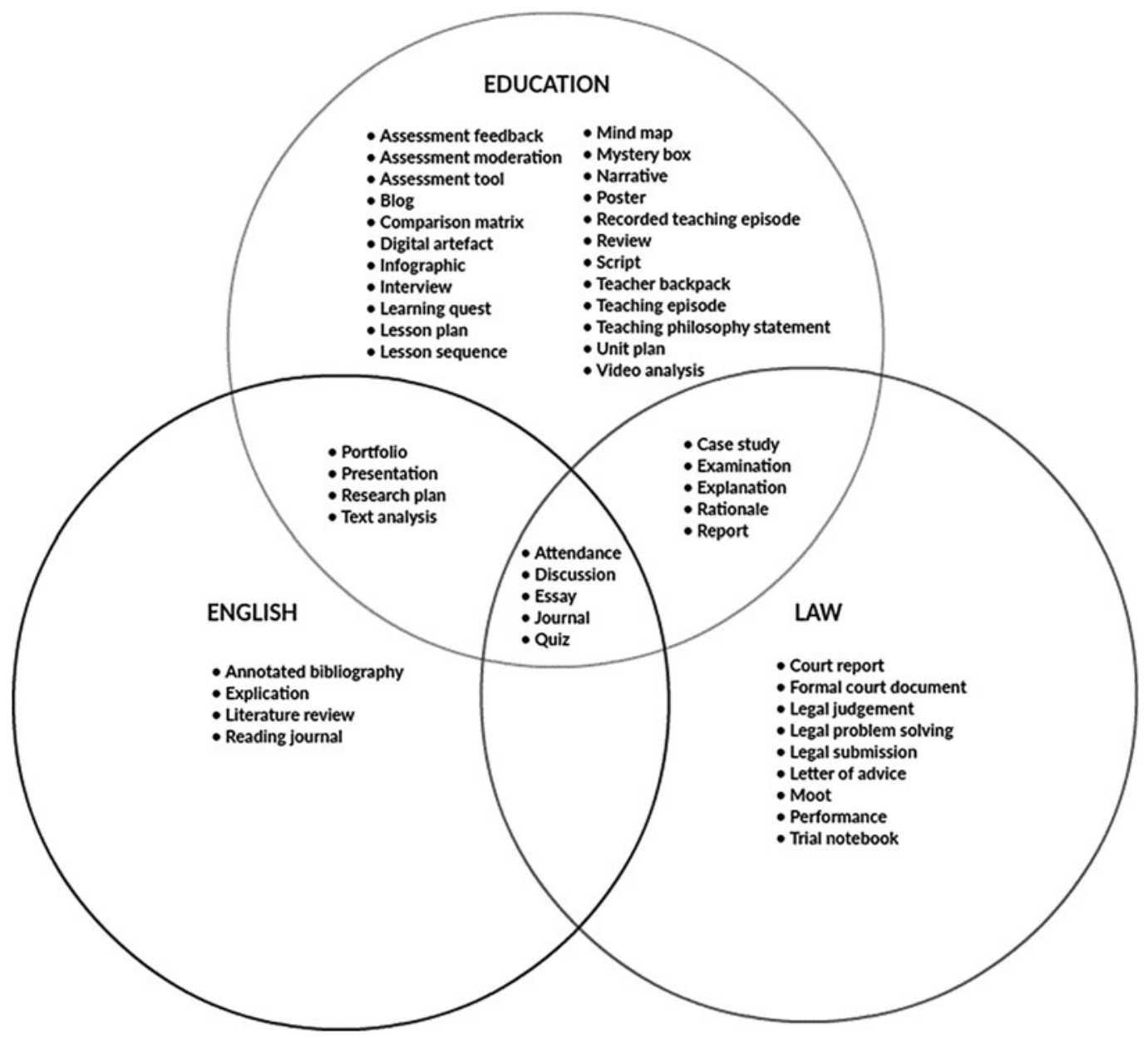

Figure 7. Assessment formats in the three degrees.

cases, with all students required to write essays, reflective journals, and responses to online quizzes, to discuss ideas in tutorial contexts, and to be physically present in tutorials. In addition, a set of four assessment formats were common across education and English, while five formats were common across education and law (see Figure 7). The analysis found that no assessment formats were common between law and English only.

Beyond the more common assessment formats, the analysis identified an additional 23 formats unique to education, while nine were unique to law, and four to English. This highlights the intimidating range of unique formats that education students in this degree were required to address. While further research into the assessment details of education degrees at other institutions would provide a useful comparison, the results of this study suggest these education students needed to communicate understandings in unique ways in most units. Law and English students had a more consistent assessment experience, with lecturers privileging a smaller range of formats. One method education lecturers might use to assist students to contend with the diversity of their assessment experience would be to consistently and explicitly define the rhetorical purpose, format, mode and group arrangements of assessments in their units.

The analysis identified a favouring of written assessments in the three degrees. This raises several issues concerning accessibility for diverse student populations, many of whom may communicate more proficiently in other modes. The analysis showed that while some assessments in the degrees suited written communication, others could feasibly have assessed student 
knowledge and skills orally, visually or through other modes. Assessment through oral language was the next most common mode in law and English, while only 7\% of assessments in education were assessed through oral communication. This represents an area for attention for education lecturers at this university, given that most of learning in schools occurs through verbal communication between teachers and students (Rahman 2010; Johnston, Ivey, and Faulkner 2011). Despite this, the education degree's assessment of the visual mode in $24 \%$ of tasks reflects a recognition of the role played by visual information in learning in educational settings.

While the promotion of heroically individualised practice can justify the lack of group tasks in English (Leane, Fletcher, and Garg 2017), the clear focus on individual assessment in education units may represent another area for future attention. This may better reflect shifts in school settings towards team teaching, planning and reflecting over the past three decades (Vescio, Ross, and Adams 2008), particularly given the Teacher Professional Standards around engaging professionally with colleagues in school communities (AITSL 2017). Most tasks in the law degree also involved the assessment of individuals (i.e. 86\%), yet included a range of group assessments (14\%) to allow students to meet the TLO around communication and collaboration (Australian Learning and Teaching Council 2010).

\section{How might the AHEF be useful for higher education stakeholders?}

The AHEF may assist lecturers to conceptualise and present assessment aims in ways that students can effectively interpret and address, particularly when compared to descriptions that communicate assessment aims implicitly through verbs (Coffin et al. 2003). This use may positively impact student attitudes about university assessment processes, as task success is more clearly signposted.

Lecturers may also use the AHEF to identify whether the expression of assessment aims in course documents faithfully reflects the reality of assessments in the unit. Ensuring that the rhetorical purpose(s), format(s), mode(s) and group arrangement(s) of a given task as stated in course documents are consistent with other contexts when assessment aims are communicated (such as during lectures, tutorials, etc.), may increase the likelihood that students correctly interpret and address the aims of what is actually sought and assessed in the unit.

In the rush to link all aspects of units to broad learning outcomes and assessment requirements (Biggs and Tang 2011), there is increased emphasis on accountability and auditing for lecturers who must provide evidence that graduates have achieved learning outcomes. In cultures where assessment is a high-value aspect of tertiary study (Boud et al. 2010), it is useful for lecturers and faculty leadership to consider broad patterns of assessment across degree programmes. As demonstrated in the analyses, this process can reveal aspects of assessment regimes that may require attention. Assessment is how students in higher education learn, how lecturers prove they have learnt, and how students prepare for the future. Lecturers can use the AHEF to make assessment aims more explicit, increasing the likelihood that students will interpret and address these requirements in ways deemed appropriate.

The research team is cautious about contributing to a neoliberal model in which accountability agendas drive particular processes of certification, yet at the same time, sees benefit in being explicit about task requirements to address student learning and well-being needs. Trials of the AHEF to structure the communication of assessment aims would provide useful insights into whether this positively influences student attitudes, confidence and capacity to meet learning outcomes. Further research may also investigate how the framework enables and constrains assessment design processes. The research team advocates for lecturers to continue to have their professional legitimacy recognised via freedom of choice in assessment design, but sees value in providing a common framework for the design and interpretation of assessments through the same lens. 


\section{Disclosure statement}

No potential conflict of interest was reported by the authors.

\section{Notes on contributors}

Damon Thomas is a Lecturer in English Education at the University of Tasmania's College of Arts, Law and Education. His PhD research examined the rhetorical choices made by primary and secondary school students who scored highly on Australia's standardised writing test (NAPLAN) and critiqued the test as a form of writing assessment. His research interests include writing development and pedagogy, social semiotics, theories of persuasive communication, standardised testing and personalised learning.

Robbie Moore is a Lecturer in English, and the First Year English Coordinator, in the School of Humanities at the University of Tasmania. His research focusses on space and place in late-Victorian and modernist literature and culture.

Olivia Rundle is a Senior Lecturer in the Faculty of Law in the College of Arts, Law and Education at the University of Tasmania. She takes a creative and innovative approach to legal education, teaching within the practice-centric stream of units where learning activities and assessments model post-graduation professional activities. Her research spans across a range of multi-disciplinary areas, including dispute resolution, conflict management, legal education, family law, psychological wellbeing, and diversity of sex, gender and sexuality.

Sherridan Emery is a PhD candidate and an active researcher across a range of school and community-based research collaborations at the University of Tasmania relating to wellbeing. Her PhD project explores teachers' perspectives of cultural wellbeing in classroom communities.

Robyn Greaves is a Policy Analyst in the Tasmanian Department of Education. Her PhD examined mid-twentieth century Australian writers and interrogated literary reception, print culture, identity and gender. Her research interests include curriculum development, literacy, place and space, Australian liteature, culture and identity, and life writing.

Kitty te Riele is Deputy Director (Research) in the Peter Underwood Centre for Education Attainment, at the University of Tasmania, Australia. Her key research interest is on educational policy and practice for marginalised young people.

Andy Kowaluk is Principal Education Officer for the Middle years Literacy project. He has worked with the Tasmanian Department of Education as a teacher, Principal and Curriculum Officer since 1982. His professional life has been closely associated with secondary English teaching and literacy learning.

\section{ORCID}

Damon Thomas iD http://orcid.org/0000-0001-6400-6901

Robbie Moore (iD http://orcid.org/0000-0001-7941-9258

Olivia Rundle iD http://orcid.org/0000-0002-1297-9688

Sherridan Emery (iD http://orcid.org/0000-0003-2949-2793

Robyn Greaves (iD http://orcid.org/0000-0001-6293-3891

Kitty te Riele (D) http://orcid.org/0000-0002-8826-1701

Andy Kowaluk iD http://orcid.org/0000-0002-1567-373X

\section{References}

AITSL (Australian Institute for Teaching and School Leadership). 2017. "Australian Professional Standards for Teachers." AITSL. Accessed 10 June 2018. https://www.aitsl.edu.au/teach/standards

Australian Learning and Teaching Council. 2010. "Good Practice Guide (Bachelor of Laws)." ALTC. Accessed 5 June 2018. http://www.lawteachnetwork.org/resources/gpg-reflection.pdf

Baron, P., and L. C. Corbin. 2016. "Ethics Begin at Home." Legal Ethics 19 (2): 281-293.

Battershill, C., and S. Ross. 2017. Using Digital Humanities in the Classroom: A Practical Introduction for Teachers, Lecturers, and Students. London: Bloomsbury. 
Battershill, C., H. Southworth, A. Staveley, M. Widner, E. Willson Gordon, and N. Wilson. 2017. Scholarly Adventures in Digital Humanities. Houndmills: Palgrave Macmillan.

Bearman, M., P. Dawson, S. Bennett, M. Hall, E. Molloy, D. Boud, and G. Joughin. 2017. "How University Teachers Design Assessments: A Cross-Disciplinary Study." Higher Education 74 (1): 49-64.

Biggs, J. B., and C. Tang. 2011. Teaching for Quality Learning at University. 4th ed. Maidenhead: McGraw Hill.

Bloom, B. S., M. D. Engelhart, E. J. Furst, W. H. Hill, and D. R. Krathwohl. 1956. Taxonomy of Educational Objectives: The Classification of Educational Goals. New York, NY: David McKay Company.

Boud, D. 2000. "Sustainable Assessment: Rethinking Assessment for the Learning Society." Studies in Continuing Education 22 (2): 151-167.

Boud, D., and N. Falchikov. 2006. "Aligning Assessment with Long Term Learning." Assessment and Evaluation in Higher Education 31 (4): 399-413.

Boud, D., R. Sadler, G. Joughin, R. James, M. Freeman, S. Kift, F. Dochy, et al. 2010. Assessment 2020: Seven Propositions for Assessment Reform in Higher Education. Sydney: Australian Learning and Teaching Council.

Broadfoot, P., and P. Black. 2004. "Redefining Assessment? the First Ten Years of Assessment in Education." Assessment in Education: Principles, Policy \& Practice 11 (1): 7-26.

Chambers, E., and M. W. Gregory. 2006. Teaching and Learning English Literature. London: Sage.

Clarke, D., and H. Hollingsworth. 2002. "Elaborating a Model of Teacher Professional Growth." Teaching and Teacher Education 18 (8): 947-967.

Coffin, C., M. J. Curry, S. Goodman, A. Hewings, T. M. Lillis, and J. Swann. 2003. Teaching Academic Writing: A Toolkit for Higher Education. London: Routledge.

Cope, B., and M. Kalantzis. 2009. "Multiliteracies: New Literacies, New Learning." Pedagogies: An International Journal 4 (3): 164-195.

de Silva Joyce, H., S. Feez, E. Chan, and S. Tobias. 2014. "Investigating the Literacy, Numeracy and ICT Demands of Primary Teacher Education." Australian Journal of Teacher Education 39 (9): 111-129.

Ehrenberg, S. 2017. "Teaching the Neglected Art of Persuasive Writing." Legal Education Review 26 (1): 2-23.

Fisher, R., W. Ury, and B. Patton. 1991. Getting to Yes: Negotiating an Agreement without Giving In. 2nd ed. Sydney, NSW: Century Business.

Gibson, J. 2017. "Beyond the Essay? Assessment and English Literature." In Teaching Literature: Text and Dialogue in the English Classroom, edited by Ben Knights, 99-114. London: Palgrave Macmillan.

Goodman, A. 2012. Effective Written Advocacy: A Guide for Practitioners. 2nd ed. London: Wildy, Simmons and Hill Publishing.

Hattie, J. 2012. Visible Learning for Teachers: Maximising Impact on Learning. New York, NY: Routledge.

Heath, G. 2011. ACDE Project: Bachelor Degrees in Education Threshold Learning Outcomes. Canberra, ACT: ACDE.

Houldsworth, C., and B. P. Mathews. 2000. "Group Composition, Performance and Educational Attainment." Education \& Training 42 (1): 40-53.

Hughes, J. C. 2002. "Tools and Techniques for Enhancing the Quality and Effectiveness of Student Teams. In Quality Conversations, edited by T. Herrington, 114-118. ACT, Australia: HERDSA.

Hussein, A. 2009. "The Use of Triangulation in Social Sciences Research: Can Qualitative and Quantitative Methods Be Combined?" Journal of Comparative Social Work 1: 1-12.

Johnston, P. H., G. Ivey, and A. Faulkner. 2011. "Talking in Class: Remembering What Is Important about Classroom Talk." The Reading Teacher 65 (4): 232-237.

Knights, B. 2017. Pedagogic Criticism: Reconfiguring University English Studies. London: Palgrave Macmillan.

Leane, E., L. Fletcher, and S. Garg. 2017. "Co-Authorship Trends in English Literary Studies, 1995-2015." Studies in Higher Education 1-13. doi:10.1080/03075079.2017.1405256

Linkon, S. L. 2011. Literary Learning: Teaching the English Major. Bloomington, IN: Indiana University Press.

McLean, H. 2018. "This Is the Way to Teach: Insights from Academics and Students about Assessment That Supports Learning." Assessment \& Evaluation in Higher Education. Advance Online Publication. doi:10.1080/ 026022938.2018.1446508

Meyer, L. H., S. Davidson, L. McKenzie, M. Rees, H. Anderson, R. Fletcher, P. M. Johnston, et al. 2010. "An Investigation of Tertiary Assessment Policy and Practice: Alignment and Contradictions." Higher Education Quarterly 64 (3): 331-350.

O'Leary, Z. 2004. The Essential Guide to Doing Research. Thousand Oaks, CA: Sage.

Office for Learning and Teaching. 2014. "Threshold Learning Outcomes." Office for Learning and Teaching. Accessed 1 June 2018. http://www.firstyearlearningthresholds.edu.au/english/threshold-learning-outcomes

Quality Assurance Agency for Higher Education. 2015. Subject Benchmark Statement. Gloucester, UK: Quality Assurance Agency for Higher Education.

Rahman, M. 2010. "Teaching Oral Communication Skills: A Task-Based Approach." English for Specific Purposes World 9 (1): 1-11.

Ramsden, P. 2003. Learning to Teach in Higher Education. 2nd ed. London: Routledge Falmer.

Schon, D. A. 1983. The Reflective Practitioner: How Professionals Think in Action. New York, NY: Basic Books. 
Thomson, E., and L. Droga. 2012. Effective Academic Writing: An Essay-Writing Handbook for School and University. Putney, NSW: Phoenix Education.

Vescio, V., D. Ross, and A. Adams. 2008. "A Review of Research on the Impact of Professional Learning Communities on Teaching Practice and Student Learning." Teacher and Teaching Evaluation: An International Journal of Research and Studies 24 (1): 80-91.

Villarroel, V., S. Bloxham, D. Bruna, C. Bruna, and C. Herrera-Seda. 2017. "Authentic Assessment: Creating a Blueprint for Course Design." Assessment \& Evaluation in Higher Education 43 (5): 840-854. doi:10.1080/ 02602938.2017 .1412396

Wiliam, D. 2007. "Keeping Learning on Track: Formative Assessment and the Regulation of Learning." In Second Handbook of Mathematics Teaching and Learning, edited by F. K. Lester, 1053-1098. Greenwich, CT: Information Age.

Wolski, B. 2009. "Beyond Mooting: Designing an Advocacy, Ethics and Values Matrix for the Law School Curriculum." Legal Education Review 19 (1 and 2): 41-82.

Yin, R. K. 2009. Case Study Research: Design and Methods. 4th ed. Thousand Oaks, CA: Sage. 